\title{
Diiron Hexacarbonyl Complex Induces Site-Specific Release of Carbon Monoxide in Cancer Cells Triggered by Endogenous Glutathione
}

\author{
Cunji Gao, ${ }^{\dagger}$ Xiaohua Liang, ${ }^{\dagger}$ Zhengxi Guo, $^{\dagger}$ Bang-Ping Jiang, ${ }^{\dagger}$ Xiaoming Liu, ${ }^{\ddagger}$ and Xing-Can Shen ${ }^{\dagger}{ }^{\dagger}$ \\ ${ }^{\dagger}$ State Key Laboratory for Chemistry and Molecular Engineering of Medicinal Resources, School of Chemistry and Pharmaceutical \\ Sciences, Guangxi Normal University, Guilin 541004, P. R. China \\ ${ }^{\ddagger}$ College of Biological, Chemical Sciences and Engineering, Jiaxing University, Jiaxing 314001, P. R. China
}

Supporting Information

ABSTRACT: In this study, we have evaluated a water-soluble, nontarget reagent and a carrier-free diiron hexacarbonyl complex, $\left[\mathrm{Fe}_{2}\left\{\mu-\mathrm{SCH}_{2} \mathrm{CH}(\mathrm{OH})\right.\right.$ $\left.\left.\mathrm{CH}_{2}(\mathrm{OH})\right\}_{2}(\mathrm{CO})_{6}\right]$ (TG-FeCORM), that can induce the site-specific release of carbon monoxide (CO) in cancer cells triggered by endogenous glutathione (GSH). The releasing rate of $\mathrm{CO}$ was dependent on the amount of endogenous GSH. Being the amount of endogenous GSH higher in cancer cells than in normal cells, the CO-releasing rate resulted faster in cancer cells. Moreover, the anti-inflammatory properties related to the intracellular CO release of TGFeCORM were also confirmed in the living HeLa cells.

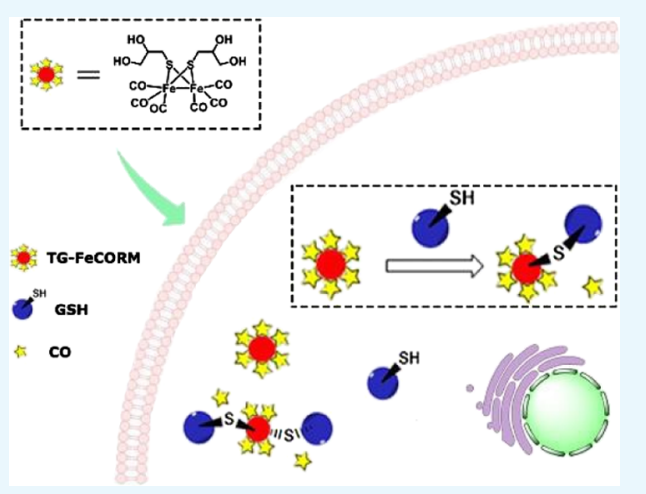

\section{INTRODUCTION}

Carbon monoxide ( $\mathrm{CO}$ ) as one of the byproducts of heme catabolism through heme oxygenase- 1 has been admitted as an endogenous vital messenger molecule in mammals. ${ }^{1-3} \mathrm{CO}$ plays many important roles in protecting tissue via its antiproliferative and anti-inflammatory effects. ${ }^{4-6}$ Thus, CO appears to have great potentials in therapeutic applications. Unfortunately, $\mathrm{CO}$ is also a highly toxic gas because of its high binding capability with hemoglobin and myoglobin. ${ }^{1,2}$ The precise control of $\mathrm{CO}$ location is one of the critical factors for useful therapeutic responses. CO-releasing molecules (CORMs) have been used to simulate the therapeutic effect of $\mathrm{CO}$ in a few biological conditions. ${ }^{7}$ Organometallic carbonyl complexes are well-suited to be candidates as CORMs. ${ }^{8-10}$ Among organometallic carbonyl complexes, CORM-2 and water-soluble CORM-3 are currently the most frequently used CORMs for investigating physiological functions of $\mathrm{CO}$ release both in vitro and in vivo. ${ }^{8} \mathrm{CO}$ release from CORMs in tissues for treatment requires safe conditions. Therefore, site-specific CORMs as therapeutic agents represent a crucial point to be evaluated. To date, organic photo-CORMs, ${ }^{11}$ micellesCORMs, ${ }^{12}$ nanocarrier CORMs, ${ }^{13}$ and bovine serum albumin ${ }^{14}$ have been explored for the site-specific CO release. However, only several nontarget reagents and carrier-free CORMs for site-specific $\mathrm{CO}$ release have yet been reported. ${ }^{10 \mathrm{~d}, \mathrm{p}}$ In addition, many CORMs have a fast CO-releasing rate in physiological buffer, with a short half-life $\left(t_{1 / 2}\right){ }^{8}$ Stable CORMs with longer $t_{1 / 2}$ are required to improve the functions and bioavailability. Therefore, novel transition metal carbonyl complexes that are suitable for site-specific CO release with high biocompatibility, excellent bioavailability, and low cost need to be further investigated.

$\left[\mathrm{Fe}_{2}\left\{\mu-\mathrm{SCH}_{2} \mathrm{CH}(\mathrm{OH}) \mathrm{CH}_{2}(\mathrm{OH})\right\}_{2}(\mathrm{CO})_{6}\right]$ (TG-FeCORM) is a water-soluble organometallic diiron hexacarbonyl compound, which has been reported in our previous work. ${ }^{15}$ TGFeCORM releases $\mathrm{CO}$ through substitution reaction by thiol groups of cysteamine (CysA). Because iron is an essential element in human life, TG-FeCORM was confirmed to be biocompatible. ${ }^{15}$ It is known that glutathione (GSH) has a thiol group and its concentration is different in normal cells $(\sim 2$ $\mathrm{mM})$ and cancer cells $(\sim 10 \mathrm{mM}) .^{16-18}$ Herein, we reported that GSH could stimulate TG-FeCORM to release CO in a concentration-dependent way. Moreover, we observed for the first time that the CO-releasing rate of TG-FeCORM triggered by GSH was significantly different in normal and cancer cells. As a transition metal carbonyl complex, TG-FeCORM is able to achieve site-specific release of $\mathrm{CO}$ in cancer cells (Scheme 1).

\section{RESULTS AND DISCUSSION}

The kinetic analysis of CO release from TG-FeCORM was monitored by UV-vis spectroscopy using the myoglobin assay. The high-intensity absorbance Soret band, nearly $420 \mathrm{~nm}$, was also observed here. ${ }^{19}$ Linear variations were not apparent for

Received: January 10, 2018

Accepted: February 22, 2018

Published: March 6, 2018 
Scheme 1. Schematic Illustration of TG-FeCORM Synthesis and Its Proposal Site-Specific CO Release in Cancer Cells Triggered by Endogenous GSH

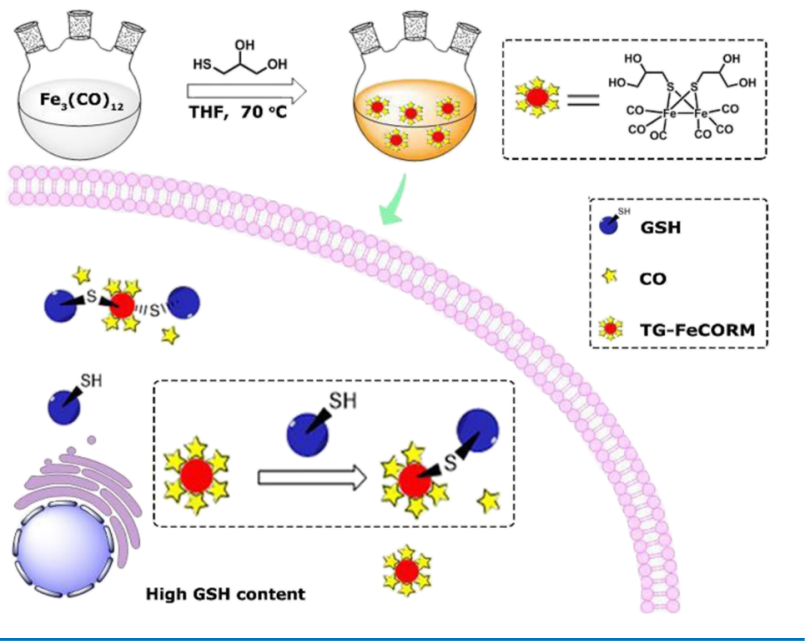

the analysis of $\mathrm{CO}$ release. Therefore, the release of $\mathrm{CO}$ from TG-FeCORM triggered by GSH was investigated by monitoring the absorption wavelength between 500 and 600 $\mathrm{nm}$, and two new absorption peaks at 540 and $577 \mathrm{~nm}$ were observed that belong to the $\mathrm{Q}$ band region of $\mathrm{MbCO}$ (Figure S1). ${ }^{10 e, n, 20}$ Without GSH, TG-FeCORM completely released $\mathrm{CO}$ in $760 \mathrm{~min}$, and the $t_{1 / 2}$ was $480 \mathrm{~min}$ (Figure 1a, Table S1, Supporting Information). The result was caused by a reducing agent, sodium dithionite, which was used to reduce deoxymyoglobin. ${ }^{10, \mathrm{n}}$ In our previous study, TG-FeCORM did not decompose until $150 \mathrm{~min}$ in the physiological saline detected by infrared spectroscopy. ${ }^{15 \mathrm{~b}}$ Therefore, TG-FeCORM in physiological conditions is very stable. Upon the addition of $2 \mathrm{mM}$ GSH, CO was released completely in $255 \mathrm{~min}$ with a $t_{1 / 2}$ of $125 \mathrm{~min}$ (Figure $1 \mathrm{~b}$, Table S1, Supporting Information). With $10 \mathrm{mM}$ GSH, CO was completely released in $105 \mathrm{~min}$ with a $t_{1 / 2}$ of about $53 \mathrm{~min}$ (Figure 1c, Table S1, Supporting Information). Overall, the CO-releasing rate depended on the amount of GSH (Figure 1d). The intracellular endogenous GSH concentration is $\sim 2 \mathrm{mM}$ in normal cells. ${ }^{17}$ Whereas the concentration of endogenous GSH in cancer cells is 4 times that of normal cells. ${ }^{18}$ As indicated by our results, it is inferred that differences in GSH concentrations could lead to significant differences of CO release from TG-FeCORM.

TG-FeCORM had excellent cell compatibility when its concentration was less than $80 \mu \mathrm{mol} / \mathrm{L}$ in vitro (Figures S2S7, Supporting Information). The intracellular concentrations of GSH in normal cells (HL-7702) and cancer cells (BEL-7402 and $\mathrm{HeLa}$ ) were detected according to a commercial GSH assay kit. ${ }^{21}$ Intracellular GSH concentrations of HL-7702, BEL7402, and HeLa cells were determined to be approximately $3 \pm$ $1,14 \pm 2$, and $12 \pm 1 \mathrm{mM}$, respectively. The measured concentrations of endogenous GSH in cells are consistent with the data detected by the Yang's group. ${ }^{21}$ The results confirmed that there are about fourfold or fivefold higher concentrations of endogenous GSH in BEL-7402 and HeLa cells over HL7702 cells. The concentration difference of endogenous GSH between normal cells and cancer cells is in accordance with the results of the Kuppusamy's group. ${ }^{18} \mathrm{CO}$ release from TGFeCORM triggered by endogenous GSH was further evaluated in vitro. Intracellular CO-releasing profiles were measured using COP-1, a CO-responsive turn-on fluorescent probe, with a limit of detection of $1 \mu \mathrm{M}(\sim 28 \mathrm{ppb}) .^{22}$ In contrast to the negative control (Figure 2, top row), clear green fluorescent signals were observed when HeLa cells were treated with the positive control CORM-3 (Figure 2, middle row), as well as TGFeCORM (Figure 2, bottom row), confirming that both CORM-3 and TG-FeCORM could release CO in the living HeLa cells. The time-dependent mean value of total

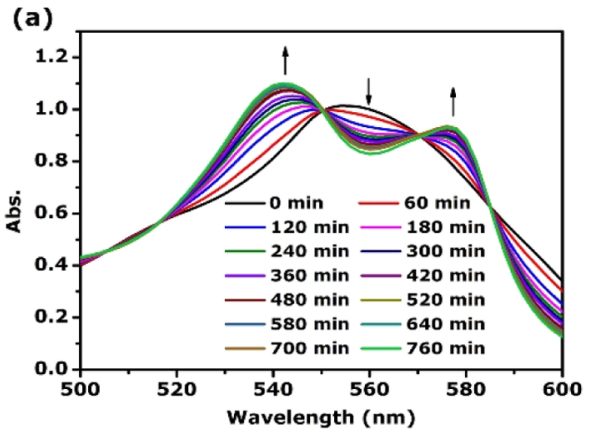

(c)

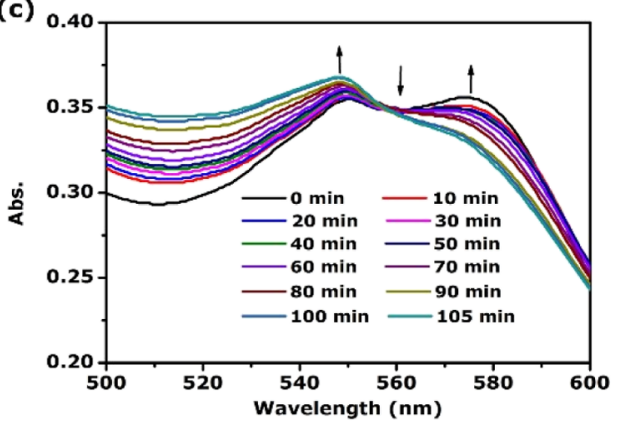

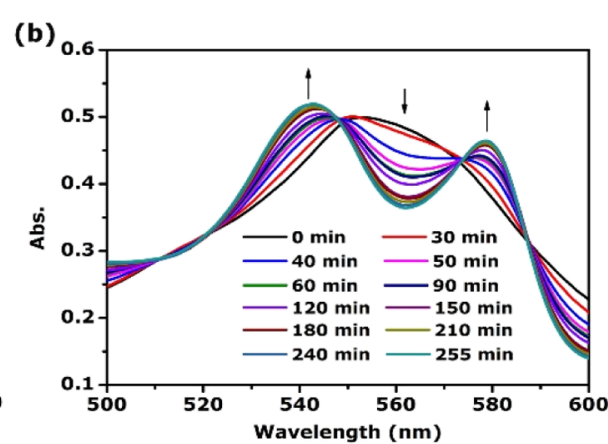

(d)

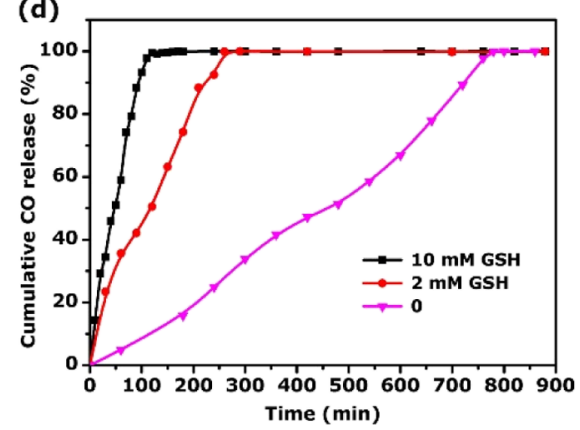

Figure 1. Time-dependent UV-vis absorption spectra of TG-FeCORM in the absence of GSH (a), and in the presence of $2 \mathrm{mM}$ GSH (b), and 10 mM GSH (c). CO release by TG-FeCORM $(20 \mu \mathrm{M})$ triggered by different concentrations of GSH vs time in reduced deoxymyoglobin (d). All of the myoglobin assays were carried out at $37{ }^{\circ} \mathrm{C}$ in phosphate buffer solution. 

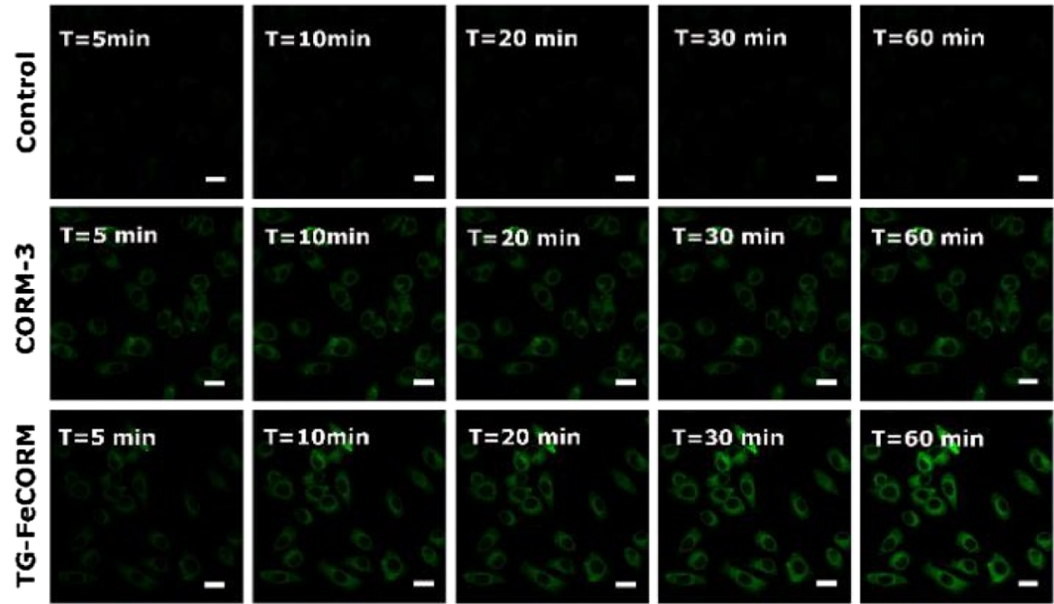

Figure 2. Time-dependent confocal microscopy images of CO site-specific release by TG-FeCORM in living HeLa cells. HeLa cells were preincubated with nothing (top row), $20 \mu \mathrm{M}$ CORM-3 (middle row), and $20 \mu \mathrm{M}$ TG-FeCORM (bottom row) for 30 min. All samples were incubated with $1 \mu \mathrm{M}$ COP-1 for $30 \mathrm{~min}$. Images were taken every $10 \mathrm{~min}$. Scale bars: $20 \mu \mathrm{m}$.

fluorescence intensity of living HeLa cells was integrated at the same condition to test the CO-releasing process (Figure S8, Supporting Information). CO release from CORM-3 or TGFeCORM was fast in the first $5 \mathrm{~min}$. The nonsignificant change of fluorescence intensity indicates that the $\mathrm{CO}$ release from CORM-3 did not change during 10-60 min (Figures 2 and S8, Supporting Information). By contrast, the evident increase of fluorescence intensity suggests that $\mathrm{CO}$ release from TGFeCORM is continuous within $60 \mathrm{~min}$ (Figures 2 and S8, Supporting Information). Thus, the releasing time of TGFeCORM is more durable than CORM-3 in living HeLa cells. With $10 \mathrm{mM}$ GSH, CO was completely released in $105 \mathrm{~min}$, according to the myoglobin assay. The detected endogenous GSH concentration in HeLa cells is about $12 \mathrm{mM}$. Consequently, CO may be completely released from TGFeCORM in about 100 min combined with the above results.

The performances of CO release from TG-FeCORM were further investigated with fluorescence imaging experiments, carried out in vitro using normal cells (HL-7702) and cancer cells (BEL-7402 and HeLa). As shown in Figure 3a, green fluorescence was very weak in HL-7702 treated with COP-1 to detect $\mathrm{CO}$ release, indicating that the amount of $\mathrm{CO}$ release by TG-FeCORM triggered by endogenous GSH was very low. In contrast, the green fluorescence was remarkably enhanced in BEL-7402 and HeLa cells, indicating that released CO in cancer cells was clearly higher compared to that in normal cells. These results demonstrated that the differences in the concentration of endogenous GSH could lead to a site-specific $\mathrm{CO}$ release from TG-FeCORM in cancer cells. We also evaluated the effect of CORM-3 in vitro. The fluorescence signals were observed in HL-7702, BEL-7402, and HeLa cells (Figure 3b), showing that CORM-3 could not achieve site-specific CO release in cancer cells. In contrast, TG-FeCORM could lead to the site-specific $\mathrm{CO}$ release triggered by endogenous GSH in cancer cells. For HL-7702 cells, fluorescence induced by TG-FeCORM is weak, as shown in Figure 3a, whereas that induced by CORM-3 is very strong, as shown in Figure $3 \mathrm{~b}$. Thus, compared to CORM3, TG-FeCORM is relatively stable in normal cells.

To confirm the anti-inflammatory effect of $\mathrm{CO}$ release from TG-FeCORM, the expression levels of inflammatory cytokines were detected with the enzyme-linked immunosorbent assay (ELISA). The proinflammatory cytokines IL-6, IL-1 $\alpha$, an anti-
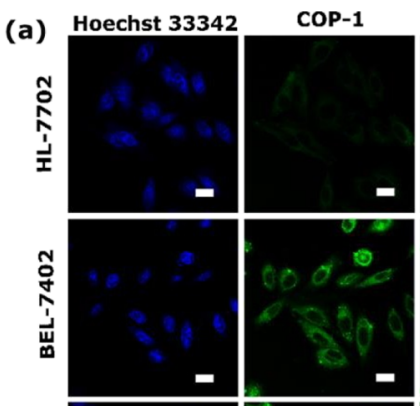

Merged
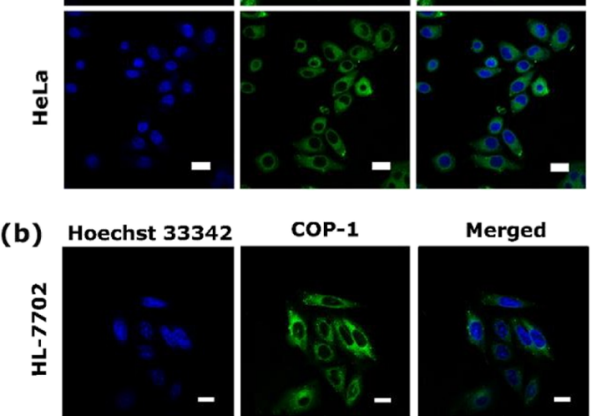

Merged
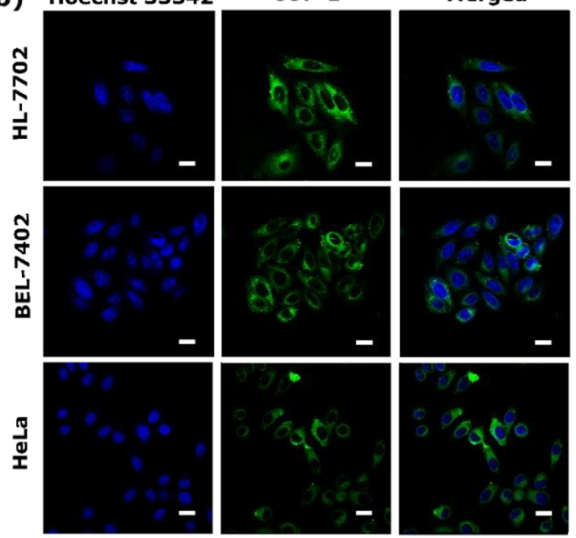

Figure 3. Confocal microscopy images for cellular $\mathrm{CO}$ release from TG-FeCORM (a), CORM-3 (b) in living HL-7702, BEL-7402, and HeLa cells, respectively. Images were taken after the treatment with 20 $\mu \mathrm{M}$ TG-FeCORM (a), $20 \mu \mathrm{M}$ CORM-3 (b), and Hoechst 33342 for $30 \mathrm{~min}$, followed by $1 \mu \mathrm{M}$ COP- 1 for $30 \mathrm{~min}$. In each panel, left pictures show the nucleus stained using Hoechst 33342 (blue), middle pictures show COP-1 detected by $\mathrm{CO}$ with turn-on signal (green), and right pictures show merged images. Scale bars: $20 \mu \mathrm{m}$.

inflammatory cytokine IL-10, and a tumor necrosis factor TNF$\alpha$ in HeLa cells were stimulated by lipopolysaccharides (LPS) in vitro. ${ }^{9,13 b, 23}$ LPS had no distinct cytotoxicity toward HeLa 
cells in the range of $0-100 \mu \mathrm{mol} / \mathrm{L}$ (Figure S9, Supporting Information). TG-FeCORM had excellent cell compatibility to HeLa cells when its concentration is in the range of $0-40$ $\mu \mathrm{mol} / \mathrm{L}$ (Figure S10, Supporting Information). As shown in Figure 4, HeLa cells displayed a positive inflammatory response

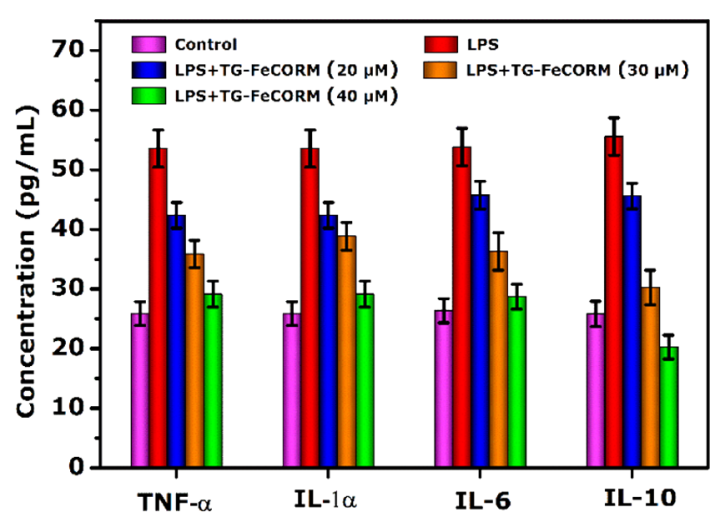

Figure 4. Effect of TG-FeCORM on the expression of TNF- $\alpha$, IL- $1 \alpha$, IL-6, and IL-10 in LPS-stimulated HeLa cells. LPS $(10 \mu \mathrm{g} / \mathrm{mL})$ was employed to stimulate to produce inflammatory cytokines. Untreated cells were employed as controls. The incubation time of TGFeCORM was $24 \mathrm{~h}$. Differences were defined as significant at $*_{p}<$ 0.05 .

with the LPS stimulated, as the concentrations of IL-6, IL- $1 \alpha$, IL-10, and TNF- $\alpha$ increased remarkably (red bars). However, the expression levels of IL-6, IL- $1 \alpha$, IL-10, and TNF- $\alpha$ were continuously decreased with the concentration of TGFeCORM rising from 20 to $40 \mu \mathrm{mol} / \mathrm{L}$. The result showed that the treatment of $\mathrm{HeLa}$ cells with TG-FeCORM significantly decreased the expression levels of IL-6, IL- $1 \alpha$, IL-10, and TNF- $\alpha$ within the LPS-stimulated HeLa cells in a concentration-dependent manner. This downregulation of inflammatory cytokines indicated that TG-FeCORM exhibited the anti-inflammatory characteristics related to the intracellular $\mathrm{CO}$ release in cancer cells, and thus the anti-inflammation effect of TG-FeCORM should be attributed to the released CO in cells. In addition, the treatment with TG-FeCORM reduced the nuclear shift of p50 and p65 in LPS-stimulated HeLa cells (Figure S11, Supporting Information). By contrast, the total levels of $B$-actin and proliferating cell nuclear antigen were unaffected after being treated with TG-FeCORM (Figure S11, Supporting Information). It was speculated that CO release from TG-FeCORM effect on inflammatory cytokines in LPSstimulated HeLa cells might be associated with the NF-KB signaling pathway. ${ }^{9,23}$ These results are consistent with the CO release from TG-FeCORM, triggered by endogenous $\mathrm{GSH}$ in cancer cells.

\section{CONCLUSIONS}

In conclusion, our experimental results demonstrated for the first time that the water-soluble TG-FeCORM could act as an endogenous GSH-responsive CORM. We observed that CO release from TG-FeCORM was clearly dependent on the concentration of GSH, both in tubes and in cells. As indicated by our results, significant differences of endogenous GSH between normal cells and cancer cells could lead to the sitespecific CO release from TG-FeCORM in cancer cells. Moreover, the anti-inflammatory properties and the longer releasing time contributed to the potential therapeutic role of TG-FeCORM for medical applications.

\section{EXPERIMENTAL SECTION}

Materials and Apparatus. Myoglobin and 1-thioglycerol were bought from Aladdin and employed as received. HeLa, HL-7702, and BEL-7402 cell lines were bought from the Chinese Academy of Sciences.

Images were obtained by a Zeiss LSM 710 confocal laser point-scanning microscope. The ELISA test was measured using a finite M200 microplate absorbance reader, Tecan. Myoglobin kinetics assay was measured with a UV spectrophotometer (UV-2600). All reagents were purchased from commercial sources and utilized without further disposal. All solvents were freshly distilled prior to use.

Myoglobin Kinetics Assay. ${ }^{24,25}$ For the myoglobin assay, all solutions were prepared in the phosphate buffer at $\mathrm{pH}=7.4$. A myoglobin solution $(2 \mathrm{mg} / \mathrm{mL})$ was degassed through pouring into nitrogen for more than $15 \mathrm{~min}$. Then, a freshly prepared solution of sodium dithionite $(24 \mathrm{mg} / \mathrm{mL})$ with 1:10 dithionite/dexy-Mb (v/v) added to the above degassed solution, which gave a $108 \mu \mathrm{M} / \mathrm{mL}$ dexy-Mb. An appropriate amount of TG-FeCORM and GSH was added to the dexy-Mb solution (Table S1). The solution was moved quickly into a room. UV-vis spectra were taken at $37{ }^{\circ} \mathrm{C}$ at predetermined time points by a UV-vis spectrophotometer and measured with a wavelength from 600 to $500 \mathrm{~nm}$ by an interval of $2 \mathrm{~nm}$. Quantification of CO release was calculated from the obtained spectra according to the equation below (eqs 1-3).

Equation 1 was used for counting the total myoglobin quantity of saturated $\mathrm{Mb}-\mathrm{CO}$ solution. $\varepsilon$ represents the extinction coefficient while $\mathrm{Mb}-\mathrm{CO}$ is $15.4 \mathrm{mM}^{-1} \mathrm{~cm}^{-1}$ and $\mathrm{OD}_{540}$ is the absorbance of $\mathrm{Mb}-\mathrm{CO}$ solution while the wavelength is $540 \mathrm{~nm}$.

$$
\mathrm{Mb}-\mathrm{CO}_{\max }=\frac{\mathrm{OD}_{540}}{\varepsilon} \times 1000
$$

Intermediate quantities of $\mathrm{Mb}-\mathrm{CO}$ are counted by the $\mathrm{OD}_{540}$. A novel extinction coefficient $\left(\varepsilon_{2}\right)$ must be calculated to consider the altered absorbance at $540 \mathrm{~nm}\left(\Delta \mathrm{OD}_{540}\right)$. To improve the calculation accuracy, another wavelength serves as a constant reference point. There are four isosbestic $\left(\mathrm{OD}_{\text {iso }}\right)$ points $(510,550,570$, and $585 \mathrm{~nm})$ in $\mathrm{Mb}-\mathrm{CO}$ and deoxy-Mb spectra. The data at $510 \mathrm{~nm}\left(\mathrm{OD}_{\text {iso510 }}\right)$ were utilized in this set of experiments. $\varepsilon_{2}$ was calculated by eq 2 .

Equation 2 was used to count the unknown $\mathrm{Mb}-\mathrm{CO}$ extinction coefficient. $\Delta \mathrm{OD}_{\text {iso510 }}$ is the altered absorbance at the isosbestic point; $\Delta \mathrm{OD}_{540}$ is the altered absorbance at 540 $\mathrm{nm}$; and $\mathrm{Mb}-\mathrm{CO}_{\max }$ is the maximum concentration of myoglobin.

$$
\varepsilon_{2}=\left(\Delta \mathrm{OD}_{540}-\Delta \mathrm{OD}_{\text {iso510 }} \times 1000\right) / \mathrm{Mb}-\mathrm{CO}_{\max }
$$

From $\varepsilon_{2}$ and the altered absorbance of 510 and $540 \mathrm{~nm}$, the unknown myoglobin concentration will be obtained as given in eq 3, which was used to count the $\mathrm{Mb}-\mathrm{CO}$ concentration.

$$
\mathrm{Mb}-\mathrm{CO}=1000 \times \frac{\left(\Delta \mathrm{OD}_{540}-\Delta \mathrm{OD}_{\text {iso510 }}\right)}{\varepsilon_{2}}
$$

$t_{1 / 2}$ values are given as the time when the concentration of $\mathrm{Mb}-\mathrm{CO}$ is equal to half the start concentration of TGFeCORM. 
Assessing the Cytotoxicity of TG-FeCORM Using MTT Assay. HeLa cells $\left(180 \mu \mathrm{L}, 1 \times 10^{5}\right.$ cells $\left.\mathrm{mL}^{-1}\right)$ were seeded into 96 well microtitre plates and treated with $24 \mathrm{~h}$. Then, the medium in wells was abandoned and added a medium including a mixture of TG-FeCORM. In addition, the concentrations of TG-FeCORM were 10, 20, 30, 40, 50, 60, 70, 80, 90, and 100 $\mu \mathrm{mol} \cdot \mathrm{L}^{-1}$. The cells were then treated with another $24 \mathrm{~h}$ before the treatment medium took the place of the complete medium. Cells in a well without the addition of TG-FeCORM were used as a control ( $100 \%$ in cell viability). Each concentration was detected in five wells of the same plate. It was repeated three times to test the reproducibility of the assessment.

Probe COP-1 Fluorescence Response by Confocal Microscopy Imaging. Probe COP-1 was synthesized according to the literature. ${ }^{9,22}$ Images were obtained by a Zeiss LSM 710 confocal laser point-scanning microscope with a $40 \times$ oil objective lens, and a numerical aperture of 1.3. COP-1 was excited by a $488 \mathrm{~nm}$ laser, and Hoescht 33342 was excited using a diode laser $405 \mathrm{~nm}$, and they were read at green $\left(\lambda_{\mathrm{em}}=\right.$ $500-550 \mathrm{~nm})$ and blue $\left(\lambda_{\mathrm{em}}=420-470 \mathrm{~nm}\right)$, respectively. Cells were imaged at $37^{\circ} \mathrm{C}$ and $5 \% \mathrm{CO}_{2}$ throughout the course

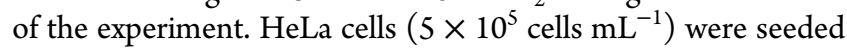
in laser confocal culture dish 2 days before the experiment. Culture conditions were the same, as used for the routine cell passage using RPMI-1640 medium. HeLa cells were preincubated with nothing (top row), $20 \mu \mathrm{M}$ CORM-3 (middle row), and $20 \mu \mathrm{M}$ TG-FeCORM (bottom row) for $30 \mathrm{~min}$, respectively, and then all of them were incubated with 1 $\mu \mathrm{M}$ COP-1 for $30 \mathrm{~min}$. Images were taken every 2 min using representative images of the experiment. Mean of total fluorescence intensity of treated TG-FeCORM or CORM-3 versus untreated cells was compared using representative images of the independent experiment. Data are presented in the graphs (Figure S7) as a mean of total fluorescent intensity.

Measurement of GSH Concentration by Commercial Assay Kit. GSH concentration of HL-7702, BEL-7402, and HeLa cells were measured by an 5,5-dithio-bis(2-nitrobenzoic) acid method used in the commercial GSH assay kit (Beyotime Institute of Biotechnology, Jiangsu, China). The absorbance at $412 \mathrm{~nm}$ was measured using a microplate reader. ${ }^{22}$

Cytokine Modulation by CO Release. ${ }^{9}$ Growth medium levels of the tested chemokines were quantified using Human IL-1 $\alpha$, IL-6, IL-10, and TNF- $\alpha$ Mini ELISA Development kits (PeproTech, sensitivity range of $0.063 \mathrm{ng} / \mathrm{mL}$ to $4 \mu \mathrm{g} / \mathrm{mL}$ ) and revealed using 3,3',5,5'-tetramethylbenzidine substrate reagent set (BD Biosciences) on the basis of the manufacturer's protocol. The absorbance in each well was detected at $450 \mathrm{~nm}$ with a microplate reader (Infinite M200 microplate absorbance reader, Tecan). Cells were plated with the $2.5 \times 10^{5}$ cell $/$ well in 6 well plates. Five groups were tested: cells were incubated with LPS or without LPS and then treated with TG-FeCORM (20$40 \mu \mathrm{M}), 48 \mathrm{~h}$ after seeding. Supernatants were collected at $24 \mathrm{~h}$ post-treatment.

Western Blot Analysis. ${ }^{26}$ Total cell lysates were collected by extracting with the NEPER kit. Concentrations of collected proteins were detected through a protein assay kit. Equal amounts of cellular total proteins were separated on $10 \%$ sodium dodecyl sulfate-polyacrylamide gel electrophoresis and then moved to polyvinylidenedifluoride membranes and sealed with $5 \%$ nonfat milk in TBST buffer $(150 \mathrm{mM} \mathrm{NaCl}, 0.05 \%$ Tween 20, $20 \mathrm{mM}$ Tris, $\mathrm{pH}=8.0$ ) for $1 \mathrm{~h}$. Then, the membranes were treated with the primary antibodies (p50 and p65) at $4{ }^{\circ} \mathrm{C}$ for $24 \mathrm{~h}$. After a subsequent washing step, the membrane was treated with the appropriate secondary antibodies conjugated with horseradish peroxidase for $2 \mathrm{~h}$ at $25{ }^{\circ} \mathrm{C}$ and washed 3 times with TBST. The immune reactivity was determined by Amersham ECL Plus western blotting detection reagents.

\section{ASSOCIATED CONTENT}

\section{Supporting Information}

The Supporting Information is available free of charge on the ACS Publications website at DOI: 10.1021/acsomega.8b00052.

UV-vis absorption spectra of reduced deoxy-Mb and $\mathrm{MbCO}$; kinetic analysis of the substitution reaction of TG-FeCORM by GSH; cytotoxicity of TG-FeCORM toward HeLa, HL-7702, BEL-7402, MGC-803, A549, and T24 cells; total fluorescence intensity of living HeLa cells; cytotoxicity of LPS and LPS + TG-FeCORM toward HeLa cancer cells; and effects of TG-FeCORM on $\mathrm{p} 65$ and $\mathrm{p} 50$ protein (PDF)

\section{AUTHOR INFORMATION}

\section{Corresponding Author}

*E-mail: xcshen@mailbox.gxnu.edu.cn (X.-C.S.).

ORCID 웅

Cunji Gao: 0000-0002-9375-7891

Notes

The authors declare no competing financial interest.

\section{ACKNOWLEDGMENTS}

Funding from the National Natural Science Foundation of China (21161003, 21364002, 21671046, 21502028, and $51562001)$ and the Guangxi Natural Science Foundation of China (2014GXNSFBA118038 and 2017GXNSFGA198004) is acknowledged. We also acknowledge the Program for New Century Excellent Talents in University of the Ministry of Education (NCET-13-0743), the Program for New Century National Hundred, Thousand and Ten Thousand Talent Project of Guangxi, and the State Key Laboratory Cultivation Base for the Chemistry and Molecular Engineering of Medicinal Resources (CMEMR2015-A02, CMEMR2013-A08, CMEMR2013-A013, and CMEMR2017-A08).

\section{REFERENCES}

(1) (a) Ryter, S. W.; Otterbein, L. E. Carbon monoxide in biology and medicine. BioEssays 2004, 26, 270-280. (b) Ryter, S. W.; Alam, J.; Choi, A. M. K. Heme oxygenase-1/carbon monoxide: From basic science to therapeutic applications. Physiol. Rev. 2006, 86, 583-650.

(2) Nakao, A.; Kimizuka, K.; Stolz, D. B.; Neto, J. S.; Kaizu, T.; Choi, A. M. K.; Uchiyama, T.; Zuckerbraun, B. S.; Nalesnik, M. A.; Otterbein, L. E.; Murase, N. Carbon monoxide inhalation protects rat intestinal grafts from ischemia/reperfusion injury. Am. J. Pathol. 2003, $163,1587-1598$.

(3) Otterbein, L. E.; Bach, F. H.; Alam, J.; Soares, M.; Lu, H. T.; Wysk, M.; Davis, R. J.; Flavell, R. A.; Choi, A. M. K. Carbon monoxide has anti-inflammatory effects involving the mitogen-activated protein kinase pathway. Nat. Med. 2000, 6, 422-428.

(4) Remy, S.; Blancou, P.; Tesson, L.; Tardif, V.; Brion, R.; Royer, P. J.; Motterlini, R.; Foresti, R.; Painchaut, M.; Pogu, S.; Gregoire, M.; Bach, J. M.; Anegon, I.; Chauveau, C. Carbon monoxide inhibits TLRinduced dendritic cell immunogenicity. J. Immunol. 2009, 182, 18771884.

(5) Pae, H.-O.; Oh, G.-S.; Choi, B.-M.; Chae, S.-C.; Kim, Y.-M.; Chung, K.-R; Chung, H.-T. Carbon monoxide produced by heme 
oxygenase-1 suppresses $\mathrm{T}$ cell proliferation via inhibition of IL-2 production. J. Immunol. 2004, 172, 4744-4751.

(6) Otterbein, L. E.; Zuckerbraun, B. S.; Haga, M.; Liu, F.; Song, R.; Usheva, A.; Stachulak, C.; Bodyak, N.; Smith, R. N.; Csizmadia, E.; Tyagi, S.; Akamatsu, Y.; Flavell, R. J.; Billiar, T. R.; Tzeng, E.; Bach, F. H.; Choi, A. M. K.; Soares, M. P. Carbon monoxide suppresses arteriosclerotic lesions associated with chronic graft rejection and with balloon injury. Nat. Med. 2003, 9, 183-190.

(7) (a) Motterlini, R; Otterbein, L. E. The therapeutic potential of carbon monoxide. Nat. Rev. Drug Discovery 2010, 9, 728-743. (b) Fagone, P.; Mangano, K.; Mammana, S.; Cavalli, E.; Di Marco, R.; Barcellona, M. L.; Salvatorelli, L.; Magro, G.; Nicoletti, F. Carbon monoxide-releasing molecule-A1 (CORM-A1) improves clinical signs of experimental autoimmune uveoretinitis (EAU) in rats. Clin. Immunol. 2015, 157, 198-204. (c) Nikolic, I.; Saksida, T.; Mangano, K.; Vujicic, M.; Stojanovic, I.; Nicoletti, F.; Stosic-Grujicic, S. Pharmacological application of carbon monoxide ameliorates isletdirected autoimmunity in mice via anti-inflammatory and antiapoptotic effects. Diabetologia 2014, 57, 980-990. (d) Fagone, P.; Mangano, K.; Quattrocchi, C.; Motterlini, R.; Di Marco, R.; Magro, G.; Penacho, N.; Romao, C. C.; Nicoletti, F. Prevention of clinical and histological signs of proteolipid protein (PLP)-induced experimental allergic encephalomyelitis (EAE) in mice by the water-soluble carbon monoxide-releasing molecule (CORM)-A1. Clin. Exp. Immunol. 2011, 163, 368-374. (e) Fagone, P.; Mangano, K.; Coco, M.; Perciavalle, V.; Garotta, G.; Romao, C. C.; Nicoletti, F. Therapeutic potential of carbon monoxide in multiple sclerosis. Clin. Exp. Immunol. 2012, 167, 179-187. (f) Wegiel, B.; Gallo, D.; Csizmadia, E.; Harris, C.; Belcher, J.; Vercellotti, G. M.; Penacho, N.; Seth, P.; Sukhatme, V.; Ahmed, A.; Pandolfi, P. P.; Helczynski, L.; Bjartell, A.; Persson, J. L.; Otterbein, L. E. Carbon monoxide expedites metabolic exhaustion to inhibit tumor growth. Cancer Res. 2013, 73, 7009-7021. (g) Nemeth, Z.; Csizmadia, E.; Vikstrom, L.; Li, M.; Bisht, K.; Feizi, A.; Otterbein, S.; Zuckerbraun, B.; Costa, D. B.; Pandolfi, P. P.; Fillinger, J.; Döme, B.; Otterbein, L. E.; Wegiel, B. Alterations of tumor microenvironment by carbon monoxide impedes lung cancer growth. Oncotarget 2016, 7, 2391923932. (h) Loureiro, A.; Bernardes, G. J. L.; Shimanovich, U.; Sárria, M. P.; Nogueira, E.; Preto, A.; Gomes, A. C.; Cavaco-Paulo, A. Folic acid-tagged protein nanoemulsions loaded with CORM-2 enhance the survival of mice bearing subcutaneous A20 lymphoma tumors. J. Nanomed. Nanotechnol. 2015, 11, 1077-1083.

(8) (a) Johnson, T. R; Mann, B. E.; Teasdale, I. P.; Adams, H.; Foresti, R.; Green, C. J.; Motterlini, R. Metal carbonyls as pharmaceuticals? $[\mathrm{Ru}(\mathrm{CO}) 3 \mathrm{Cl}$ (glycinate)], a CO- releasing molecule with an extensive aqueous solution chemistry. Dalton Trans. 2007, 1500-1508. (b) García-Gallego, S.; Bernardes, G. J. L. Carbonmonoxide-releasing molecules for the delivery of therapeutic $\mathrm{CO}$ in vivo. Angew. Chem., Int. Ed. 2014, 53, 9712-9721. (c) Motterlini, R.; Mann, B.; Johnson, T.; Clark, J.; Foresti, R.; Green, C. Bioactivity and pharmacological actions of carbon monoxide-releasing molecules. Curr. Pharm. Des. 2003, 9, 2525-2539.

(9) Chaves-Ferreira, M.; Albuquerque, I. S.; Matak-Vinkovic, D.; Coelho, A. C.; Carvalho, S. M.; Saraiva, L. M.; Romão, C. C.; Bernardes, G. J. L. Spontaneous CO release from RuII(CO)2-protein complexes in aqueous solution, cells, and mice. Angew. Chem., Int. Ed. 2015, 54, 1172-1175.

(10) (a) Wright, M. A.; Wright, J. A. PhotoCORMs: CO release moves into the visible. Dalton Trans. 2016, 45, 6801-6811. (b) Gonzalez, M. A.; Yim, M. A.; Cheng, S.; Moyes, A.; Hobbs, A. J.; Mascharak, P. K. Manganese carbonyls bearing tripodal polypyridine ligands as photoactive carbon monoxide-releasing molecules. Inorg. Chem. 2012, 51, 601-608. (c) Nobre, L. S.; Jeremias, H.; Romão, C. C.; Saraiva, L. M. Examining the antimicrobial activity and toxicity to animal cells of different types of CO-releasing molecules. Dalton Trans. 2016, 45, 1455-1466. (d) Marques, A. R.; Kromer, L.; Gallo, D. J.; Penacho, N.; Rodrigues, S. S.; Seixas, J. D.; Bernardes, G. J. L.; Reis, P. M.; Otterbein, S. L.; Ruggieri, R. A.; Gonçalves, A. S. G.; Gonçalves, A. M. L.; De Matos, M. N.; Bento, I.; Otterbein, L. E.; Blättler, W. A.; Romão, C. C. Generation of carbon monoxide releasing molecules (CO-RMs) as drug candidates for the treatment of acute liver injury: Targeting of CO-RMs to the liver. Organometallics 2012, 31, 5810-5822. (e) Reddy G, U.; Axthelm, J.; Hoffmann, P.; Taye, N.; Gläser, S.; Görls, H.; Hopkins, S. L.; Plass, W.; Neugebauer, U.; Bonnet, S.; Schiller, A. Co-registered molecular logic gate with a CO-releasing molecule triggered by light and peroxide. J. Am. Chem. Soc. 2017, 139, 4991-4994. (f) Chakraborty, I.; Carrington, S. J.; Roseman, G.; Mascharak, P. K. Synthesis, structures, and $\mathrm{CO}$ release capacity of a family of water-soluble photoCORMs: assessment of the biocompatibility and their phototoxicity toward human breast cancer cells. Inorg. Chem. 2017, 56, 1534-1545. (g) Mede, R.; Klein, M.; Claus, R. A.; Krieck, S.; Quickert, S.; Görls, H.; Neugebauer, U.; Schmitt, M.; Gessner, G.; Heinemann, S. H.; Popp, J.; Bauer, M.; Westerhausen, M. CORM-EDE1: A highly watersoluble and nontoxic manganese- based photoCORM with a biogenic ligand sphere. Inorg. Chem. 2016, 55, 104-113. (h) Li, Z.; Pierri, A. E.; Huang, P.-J.; Wu, G.; Iretskii, A. V.; Ford, P. C. Dinuclear photoCORMs: Dioxygen-assisted carbon monoxide uncaging from long-wavelength- absorbing metal-metal-bonded carbonyl complexes. Inorg. Chem. 2017, 56, 6094-6104. (i) Mede, R.; Traber, J.; Klein, M.; Görls, H.; Gessner, G.; Hoffmann, P.; Schmitt, M.; Popp, J.; Heinemann, S. H.; Neugebauer, U.; Westerhausen, M. Synthesis and solution stability of water-soluble $\kappa^{2} \mathrm{~N}, \kappa \mathrm{O}$-bis(3,5-dimethylpyrazolyl)ethanol manganese(I) tricarbonyl bromide (CORM-ONN1). Dalton Trans. 2017, 46, 1684-1693. (j) Beltrán, T. F.; Zaragoza, G.; Delaude, L. Mono- and bimetallic manganese-carbonyl complexes and clusters bearing imidazol(in)ium-2-dithiocarboxylate ligands. Dalton Trans. 2017, 46, 1779-1788. (k) Diring, S.; Carné-Sánchez, A.; Zhang, J.; Ikemura, S.; Kim, C.; Inaba, H.; Kitagawa, S.; Furukawa, S. Light responsive metal-organic frameworks as controllable CO-releasing cell culture substrates. Chem. Sci. 2017, 8, 2381-2386. (1) Jimenez, J.; Chakraborty, I.; Carrington, S. J.; Mascharak, P. K. Light- triggered $\mathrm{CO}$ delivery by a water-soluble and biocompatible manganese photoCORM. Dalton Trans. 2016, 45, 13204-13213. (m) Kottelat, E.; Ruggi, A.; Zobi, F. Red-light activated photoCORMs of Mn(I) species bearing electron deficient 2,2'-azopyridines. Dalton Trans. 2016, 45, 6920-6927. (n) Nguyen, D.; Nguyen, T.-K.; Rice, S. A.; Boyer, C. CO-releasing polymers exert antimicrobial activity. Biomacromolecules 2015, 16, 2776-2786. (o) Jazzazi, T. M. A.; Görls, H.; Gessner, G.; Heinemann, S. H.; Westerhausen, M. Photosensitive iron(II)-based CO-releasing molecules (CORMs) with vicinal amino and diphenylphosphino substituted chelating ligands. J. Organomet. Chem. 2013, 733, 63-70. (p) Pena, A. C.; Penacho, N.; Mancio-Silva, L.; Neres, R.; Seixas, J. D.; Fernandes, A. C.; Romã, C. C.; Mota, M. M.; Bernardes, G. J. L.; Pamplonaa, A. A novel carbon monoxide-releasing molecule fully protects mice from severe malaria. Antimicrob. Agents Chemother. 2012, 56, 1281-1290. (q) Atkin, A. J.; Lynam, J. M.; Moulton, B. E.; Sawle, P.; Motterlini, R.; Boyle, N. M.; Pryce, M. T.; Fairlamb, I. J. S. Modification of the deoxymyoglobin/carbonmonoxy-myoglobin UV- vis assay for reliable determination of CO-release rates from organometallic carbonyl complexes. Dalton Trans. 2011, 40, 5755-5761. (r) Rimmer, R. D.; Pierri, A. E.; Ford, P. C. Photochemically activated carbon monoxide release for biological targets. Toward developing air-stable photoCORMs labilized by visible light. Coord. Chem. Rev. 2012, 256, 15091519. (s) Rimmer, R. D.; Richter, H.; Ford, P. C. A photochemical precursor for carbon monoxide release in aerated aqueous media. Inorg. Chem. 2010, 49, 1180-1185.

(11) (a) Ji, X.; Zhou, C.; Ji, K.; Aghoghovbia, R. E.; Pan, Z.; Chittavong, V.; Ke, B.; Wang, B. Click and release: A chemical strategy toward developing gasotransmitter prodrugs by using an intramolecular Diels-Alder reaction. Angew. Chem., Int. Ed. 2016, 55, 15846-15851. (b) Palao, E.; Slanina, T.; Muchová, L.; Šolomek, T.; Vítek, L.; Klán, P. Transition-metal-free CO-releasing BODIPY derivatives activatable by visible to NIR light as promising bioactive molecules. J. Am. Chem. Soc. 2016, 138, 126-133.

(12) Hasegawa, U.; van der Vlies, A. J.; Simeoni, E.; Wandrey, C.; Hubbell, J. A. Carbon Monoxide-Releasing Micelles for Immunotherapy. J. Am. Chem. Soc. 2010, 132, 18273-18280. 
(13) (a) Kunz, P. C.; Meyer, H.; Barthel, J.; Sollazzo, S.; Schmidt, A. M.; Janiak, C. Metal carbonyls supported on iron oxide nanoparticles to trigger the $\mathrm{CO}$-asotransmitter release by magnetic heating. Chem. Commun. 2013, 49, 4896-4898. (b) He, Q.; Kiesewetter, D. O.; Qu, Y.; Fu, X.; Fan, J.; Huang, P.; Liu, Y.; Zhu, G.; Liu, Y.; Qian, Z.; Chen, $\mathrm{X}$. NIR-responsive on-demand release of $\mathrm{CO}$ from metal carbonylcaged graphene oxide nanomedicine. Adv. Mater. 2015, 27, 67416746.

(14) Fujita, K.; Tanaka, Y.; Sho, T.; Ozeki, S.; Abe, S.; Hikage, T.; Kuchimaru, T.; Kizaka-Kondoh, S.; Ueno, T. Intracellular CO release from composite of ferritin and Ruthenium carbonyl complexes. J. Am. Chem. Soc. 2014, 136, 16902-16908.

(15) (a) Long, L.; Jiang, X.; Wang, X.; Xiao, Z.; Liu, X. Water-soluble diiron hexacarbonyl complex as a CO-RM: controllable CO-releasing, releasing mechanism and biocompatibility. Dalton Trans. 2013, 42, 15663-15669. (b) Chen, L.; Jiang, X.; Wang, X.; Long, L.; Zhang, J.; $\mathrm{Liu}, \mathrm{X}$. A kinetic analysis of $\mathrm{CO}$ release from a diiron hexacarbonyl complex promoted by amino acids. New J. Chem. 2014, 38, 59575963.

(16) Jones, D. P.; Carlson, J. L.; Mody, V. C.; Cai, J.; Lynn, M. J.; Sternberg, P. Redox state of glutathione in human plasma. Free Radical Biol. Med. 2000, 28, 625-635.

(17) (a) Hassan, S. S. M.; Rechnitz, G. A. Determination of glutathione and glutathione reductase with a silver sulfide membrane electrode. Anal. Chem. 1982, 54, 1972-1976. (b) Jones, D. P.; Carlson, J. L.; Samiec, P. S.; Sternberg, P.; Mody, V. C.; Reed, R. L.; Brown, L. A. S. Glutathione measurement in human plasma evaluation of sample collection, storage and derivatization conditions for analysis of dansyl derivatives by HPLC. Clin. Chim. Acta 1998, 275, 175-184. (c) Anderson, M. E. Glutathione: an overview of biosynthesis and modulation. Chem.-Biol. Interact. 1998, 111-112, 1-14.

(18) Kuppusamy, P.; Li, H.; Ilangovan, G.; Cardounel, A. J.; Zweier, J. L.; Yamada, K.; Krishna, M. C.; Mitchell, J. B. Noninvasive imaging of tumor redox status and its modification by tissue glutathione levels. Cancer Res. 2002, 62, 307-312.

(19) Romberg, R. W.; Kassner, R. J. Nitric oxide and carbon monoxide equilibria of horse myoglobin and (TV-methylimidazole) protoheme. Evidence for steric interaction with the distal residues. Biochemistry 1979, 18, 5387-5392.

(20) (a) Motterlini, R.; Clark, J. E.; Foresti, R.; Sarathchandra, P.; Mann, B. E.; Green, C. J. Carbon monoxide-releasing molecules characterization of biochemical and vascular activities. Circ. Res. 2002, 90, E17-E24. (b) Gläser, S.; Mede, R.; Görls, H.; Seupel, S.; Bohlender, C.; Wyrwa, R.; Schirmer, S.; Dochow, S.; Reddy, G. U.; Popp, J.; Westerhausen, M.; Schiller, A. Remote-controlled delivery of $\mathrm{CO}$ via photoactive $\mathrm{CO}$-releasing materials on a fiber optical device. Dalton Trans. 2016, 45, 13222-13233.

(21) Liu, Y.; Tian, Y.; Tian, Y.; Wang, Y.; Yang, W. Carbon-dot-based nanosensors for the detection of intracellular redox state. Adv. Mater. 2015, 27, 7156-7160.

(22) Michel, B. W.; Lippert, A. R.; Chang, C. J. A Reaction-Based Fluorescent Probe for Selective Imaging of Carbon Monoxide in Living Cells Using a Palladium-mediated Carbonylation. J. Am. Chem. Soc. 2012, 134, 15668-15671.

(23) (a) Megías, J.; Busserolles, J.; Alcaraz, M. J. The carbon monoxide-releasing molecule CORM-2 inhibits the inflammatory response induced by cytokines in Caco-2 cells. Br. J. Pharmacol. 2007, 150, 977-986. (b) Sawle, P.; Foresti, R.; Mann, B. E.; Johnson, T. R.; Green, C. J.; Motterlini, R. Carbon monoxide-releasing molecules (CO-RMs) attenuate the inflammatory response elicited by lipopolysaccharide in RAW264.7 murine macrophages. Br. J. Pharmacol. 2005, 145, 800-810. (c) Bani-Hani, M. G.; Greenstein, D.; Mann, B. E.; Green, C. J.; Motterlini, R. Modulation of thrombin-induced neuroinflammation in BV-2 microglia by carbon monoxide-releasing molecule 3. J. Pharmacol. Exp. Ther. 2006, 318, 1315-1322.

(24) Matson, J. B.; Webber, M. J.; Tamboli, V. K.; Weber, B.; Stupp, $\mathrm{S}$. I. A peptide-based material for therapeutic carbon monoxide delivery. Soft Matter 2012, 8, 6689-6692.
(25) Atkin, A. J.; Lynam, J. M.; Moulton, B. E.; Sawle, P.; Motterlini, R.; Boyle, N. M.; Pryce, M. T.; Fairlamb, I. J. S. Modification of the deoxy-myoglobin/carbonmonoxy-myoglobin UV-vis assay for reliable determination of CO-release rates from organometallic carbonyl complexes. Dalton Trans. 2011, 40, 5755-5761.

(26) Lin, M.-C.; Pan, C.-Y.; Hui, C.-F.; Chen, J.-Y.; Wu, J.-L. Shrimp anti-lipopolysaccharide factor (SALF), an antimicrobial peptide, inhibits proinflammatory cytokine expressions through the MAPK and NF- $\kappa$ B pathways in LPS-induced HeLa cells. Peptides 2013, 40, $42-48$. 